\title{
PELAKSANAAN PROGRAM PENANGGULANGAN DIARE DI PUSKESMAS MATAKALI
}

\author{
Hariani $^{1}$, Ramlah ${ }^{2}$ \\ ${ }^{1}$ Kampus Universitas Al Asyariah Mandar, Fakultas Kesehatan Masyarakat. D/a. Jl. Budi Utomo \\ No.2 Manding, Kecamatan Polewali, Kabupaten Polewali Mandar, Provinsi Sulawesi Barat, \\ Indonesia \\ Email: harianitnr25@gmail.com
}

\begin{abstract}
Abstrack
Diarrhea is defecate to the consistency of liquid As many as 3 or times a year or more in one day. Two criteria is important to defecate Liquid and often, So for example defecate three times a day but not liquid, then neither can called daire and cannot be called daire. Prevention that carried out by the Puskesmas Matakali to address increasing cases of diarrhea that is the health of the environment and information with held in each of child good to seniors with a tool such as posters, leaflet, Sheets turning counseling and training to Posyandu cadres and environmental health, Who was conducted by the officer environmental health namely check canteen healthy at the school, counseling with waste management that good and monitor ownership of privy. Research aims to understand reduction programs diarrhea in Puskesmas Matakali by using the method the qualitative study the phenomenology. Informants research were 4 people that is the clinic, P2p diarrhea, Sanitarian and the affected by the case diarrhea. Namely the reduction of the data, data analysis data display images / verification and conclusions. The research results show that diarrhea reduction programs carried out, had also won three other obstacles of copies of office by officers diarrhea, A lack of an instrument counseling. The conclusion of research is the role of health workers is needed to make the program diarrhea can run optimally, low public participation in maintaining healthy environment as waste management and use privy still not comprehensive
\end{abstract}

\section{ABSTRAK}

Diare adalah buang air besar dengan konsistensi cair sebanyak 3 kali atau lebih dalam satu hari). Dua kriteria penting harus ada yaitu buang air besar cair dan sering, jadi misalnya buang air besar sehari tiga kali tapi tidak cair, maka tidak bisa disebut daire. Upaya pencegahan yang dilakukan oleh pihak Puskesmas Matakali untuk mengatasi peningkatan kasus diare yaitu penyehatan lingkungan dan penyuluhan yang dilakukan di setiap umur baik balita sampai dengan lansia dengan menggunanakan alat seperti poster, leaflet, lembar balik penyuluhan dan memberikan pelatihan kepada kader posyandu sedangakan penyehatan lingkungan yang dilakukan oleh petugas kesling yaitu memeriksa kantin sehat disekolah, memeriksa air bersih di masyarakat, penyuluhan dengan pengelolaan sampah yang baik dan mengawasi kepemilikan jamban. Penelitian ini bertujuan untuk mengetahui pelaksanaan program penanggulangan diare di Puskesmas Matakali dengan menggunakan metode penelitian kualitatif dengan pendekatan fenomenologi. Informan penelitian berjumlah 4 orang yaitu Kepala Puskesmas, P2p diare, Sanitarian dan masyarakat yang terkena kasus diare. Analisis data yaitu reduksi data, tampilan data dan kesimpulan gambar/verifikasi. Hasil penelitian menunjukkan bahwa pelaksanaan program penanggulangan diare dilaksanakan, hambatan yang didapatkan yaitu adanya rangkap jabatan oleh petugas diare, kurangnya alat penyuluhan, kurangnya partisipasi masyarakat dalam kegiatan pencegahan diare dan masyarakat yang menganggap penyakit diare tidak terlalu bahaya serta masih percaya dengan kebiasaan-kebiasaan terdahulu. Kesimpulan dari penelitian ini adalah peran dari tenaga kesehatan sangat dibutuhkan agar program diare dapat berjalan secara optimal, rendahnya partisipasi masyarakat dalam menjaga kebersihan lingkungan seperti pengolahan sampah dan penggunaan jamban yang masih belum menyeluruh.

Kata Kunci : pencegahan, Diare, Puskesmas Matakali 


\section{PENDAHULUAN}

Menurut WHO Pengertian diare adalah buang air besar dengan konsistensi cair (mencret) sebanyak 3 kali atau lebih dalam satu hari (24 jam). Ingat, dua kriteria penting harus ada yaitu buang air besar (BAB) cair dan sering, jadi misalnya buang air besar sehari tiga kali tapi tidak cair, maka tidak bisa disebut daire. Begitu juga apabila buang air besar dengan tinja cair tapi tidak sampai tiga kali dalam sehari, maka itu bukan diare (WHO, 2014).

Penyebab diare pada bayi dan anak-anak berbeda dengan penyebab diare pada orang dewasa. Kalau pada anak-anak biasanya disebabkan oleh virus, sedangkan pada orang dewasa disebabkan oleh bakteri. Diare pada orang dewasa dapat dipicu oleh beberapa faktor, misalnya karena salah makan, gangguan pencernaan makanan, pengaruh obat-obatan dan karena kondisi kejiwaan sedangkan pada bayi bisa terinfeksi jika, menelan kuman tersebut ketika melewati jalan lahir yang terkena kuman atau ketika disentuh oleh tangan yang berkuman. Anak-anak juga mudah terinfeksi kuman karena sering memasukkan tangan dan mainan mereka yang kotor kedalam mulut.

Di dunia, terdapat 1,7 miliar kasus diare yang terjadi setiap tahunnya. Sedangkan di Indonesia, menurut prevalensi yang didapat dari berbagai sumber, salah satunya pada penderita diare di Indonesia berasal dari semua umur, namun prevalensi tertinggi penyakit diare diderita oleh balita, terutama pada usia <1 tahun (7\%) dan 1-4 tahun (Riskesdas, 2013)

Berdasarkan data profil kesehatan Indonesia bahwa diare termasuk penyakit terbanyak tahun 2016 dengan 173 kasus dan telah terjadi klb dan hasil rekapitulasi dari tahun 2008-2016 penyakit diare meningkat dari $0,4 \%$ menjadi 3,04\% dengan kasus terbanyak Provinsi Jawa Barat dengan penderita 1.261.159 sedangkan Sulawesi Barat sebanyak 34.619 penderita (Profil Kesehatan Indonesia, 2016).

Berdasarkan data profil kesehatan Sulawesi Barat tahun 2016 bahwa penyakit diare tertinggi di Kabupaten Mamasa dengan penderita 32.070 dari 17 Puskesmas sedangkan Kabupaten Polewali Mandar kasus diare sebanyak 17.659 penderita (Profil Kesehatan Sulawesi Barat, 2016).

Berdasarkan data dari Dinas Kesehatan Polewali Mandar dari 20 Puskesmas yang ada di Polewali Mandar hanya 2 Puskesmas yang ditemukan kasus kematian salah satunya Puskesmas Matakali yang ditemukan kasus kematian disebabkan oleh penyakit diare (Dinas Kesehatan Polewali Mandar, 2018).

Berdasarkan data yang diperoleh dari Puskesmas Matakali pada tahun 2017 jumlah penderita diare sebanyak 1.324 penderita serta 
di temukannya 1 kasus kematian bayi yang disebabkan oleh penyakit diare dan pada tahun 2018 bulan januari-oktober jumlah penderita diare sebanyak 833 orang dengan capaian $3,61 \%$ dan target 623 penderita atau 2,70\% serta ditemukanya kembali kasus kematian yaitu 1 bayi meninggal yang disebabkan oleh penyakit diare karena lingkungan rumah yang kurang bersih, kondisi rumah serta jamban yang tidak memenuhi syarat dan lambatnya penanganan bayi tersebut (Profil Puskesmas Matakali, 2018).

Berdasarkan hasil wawancara peneliti dengan petugas puskesmas dapat diketahui bahwa program penanggulangan diare yang dilaksanakan yaitu tatalaksana penderita diare, surveilans epidemiologi, promosi kesehatan, pencegahan diare, pengelolaan logistik, pemantauan dan evaluasi. serta menjalin kerjasama dengan lintas sektoral yaitu Dinas Kesehatan Polewali Mandar dan pemerintah setempat untuk mengatasi peningkatan kasus diare. Bentuk kerjasama yang dilakukan oleh Dinas Kesehatan Polewali Mandar yaitu penyediaan obat-obatan untuk penderita diare. Adapun upaya pencegahan yang dilakukan oleh pihak Puskesmas Matakali untuk mengatasi peningkatan kasus diare yaitu penyehatan lingkungan dan penyuluhan di setiap umur baik balita sampai dengan lansia dengan menggunanakan poster, lifleat, lembar balik penyuluhan dan memberikan pelatihan kepada kader posyandu sedangakan penyehatan lingkungan yang dilakukan oleh petugas kesling yaitu memeriksa kantin sehat disekolah, memeriksa air bersih di masyarakat, penyuluhan dengan pengelolaan sampah yang baik dan mengawasi kepemilikan jamban. Untuk mengetahui Pelaksanaan Program Penanggulangan Diare di Puskesmas Matakali Kec.Matakali Kab.Polewali Mandar.

\section{BAHAN DAN METODE}

Jenis penelitian ini adalah penelitian kualitatif dengan menggunakan pendekatan fenomenologi. Penelitian ini dilaksanakan di Puskesmas Matakali pada tanggal 1februari 13 maret 2019 . Untuk meningkatkan keabsahan data penelitian ini, dilakukan triangulasi metode pengumpulan data yaitu dengan wawancara mendalam, observasi dan studi dokumen. Triangulasi sumber data juga dilakukan dengan mewawancarai informan yang berasal dari pihak yang terkait dengan permasalahan yang ada.

\section{HASIL}

\section{Karakteristik Informan}

\begin{tabular}{cccccc}
\hline No & Informan & Jenis Kelamin & Umur & Pendidikan & Jabatan \\
\hline 1. & H. Ahmad S.kep.,Ns & Laki-Laki & 46 thn & S2 & Kepala Puskesmas \\
2. & Ismalasari A.Md.Kep. & Perempuan & 31 thn & D3 & P2P Diare
\end{tabular}



3. Nurhayati.AMDKL
Perempuan
37 thn
D3
Sanitarian
4.
Hernawati
Perempuan
27 thn
SMA
Ibu yang anaknya menderita diare

Sumber : Profil Puskesmas Matakali

\section{Matriks Pernyataan Informan tentang Penyebab Diare di Puskesmas Matakali}

\begin{tabular}{|c|c|c|}
\hline Informan & Pernyataan & Terjemahan \\
\hline Petugas Diare & $\begin{array}{l}\text { Kalau penyebab diare diwilayah Puskesmas } \\
\text { Matakali itu, dari segi makanannya, sering jajan } \\
\text { sembarangan, banyak membeli makanan jadi, } \\
\text { tidak diolah sendiri begitu, jadi kualitas bersihnya } \\
\text { makanan itu, tidak dijamin to }\end{array}$ & $\begin{array}{l}\text { Penyebab diare diwilayah } \\
\text { Puskesmas Matakali yaitu } \\
\text { dari faktor makanan, } \\
\text { sering mengkonsumsi } \\
\text { makanan siap saji yang } \\
\text { belum terjamin kualitas } \\
\text { kebersihannya }\end{array}$ \\
\hline Sanitarian & $\begin{array}{l}\text { Yang saya liat di lapangan itu dek, masalah } \\
\text { utamanya itu, makanannya kayak pemeriksaan } \\
\text { kantin sekolah yang belum ada memenuhi standar. } \\
\text { Selain itu, dari lingkungannya juga bisa } \\
\text { berpengaruh, karena masyarakat masih ada yang } \\
\text { tidak mempunyai wc, saluran airnya yg belum } \\
\text { memadai. }\end{array}$ & $\begin{array}{l}\text { Masalah utama yang ada } \\
\text { yaitu makanan karena } \\
\text { belum ada kantin sekolah } \\
\text { yang memenuhi standar. } \\
\text { Lingkungan juga } \\
\text { berpengaruh seperti wc } \\
\text { dan saluran air yang belum } \\
\text { memadai }\end{array}$ \\
\hline Masyarakat & $\begin{array}{l}\text { Tidak tau mi juga, tapi nabilang dokter } \\
\text { makanannya }\end{array}$ & $\begin{array}{l}\text { Tidak tau pasti, kata } \\
\text { dokter dari segi makanan }\end{array}$ \\
\hline
\end{tabular}

Pernyataan Informan Tentang Sarana dan Prasarana yang Tersedia dalam Mendukung Pelaksanaan Program Diare di Puskesmas Matakali

\begin{tabular}{|c|c|c|}
\hline Informan & Pernyataaan & Terjemahan \\
\hline $\begin{array}{l}\text { Kepala } \\
\text { Puskesmas }\end{array}$ & Ruangan ada, tempat ada obat tersedia & $\begin{array}{l}\text { Ruangan, tempat dan obat } \\
\text { sudah tersedia }\end{array}$ \\
\hline Petugas Diare & $\begin{array}{l}\text { Ya sudah terpenuhi, seperti poster dan leaflet } \\
\text { hanya saja lembar balik penyuluhan ada, tapi } \\
\text { yang kecil kalau yang besar tidak kebagian dari } \\
\text { Dinkes tidak cukup dek. Susah kalau mauki } \\
\text { langsung bikin dek karena pakai dana lagi to jadi } \\
\text { dibikinkanpi BOK dicarikanpi jalan bagaimana } \\
\text { caranya bisa ada, dibicarakan dulu lagi, tahun ini } \\
\text { direncanakan. }\end{array}$ & $\begin{array}{l}\text { Kurangnya fasilitas dalam } \\
\text { melakukan penyuluhan, } \\
\text { dan berinisiatif } \\
\text { kedepannya mencari jalan } \\
\text { untuk mendapatkan dana }\end{array}$ \\
\hline Sanitarian & $\begin{array}{l}\text { Yang mencakup diare ini semua kan de' ada } \\
\text { limbahnya, sampahnya, Jambannya dan airnya, } \\
\text { jadi alat pemeriksaan air dan makanan yang } \\
\text { digunakan sudah ada satu paket namanya } \\
\text { inselentpro }\end{array}$ & $\begin{array}{l}\text { Yang mencakup semua } \\
\text { diare ada limbah, sampah } \\
\text { dan airnya. Alat } \\
\text { pemeriksaan air dan } \\
\text { makanan yang digunakan } \\
\text { yaitu inselentpro }\end{array}$ \\
\hline Mayarakat & Kurang tahu & $\begin{array}{l}\text { Kurang tahu tentang hal } \\
\text { itu }\end{array}$ \\
\hline
\end{tabular}




\section{Pernyataan Informan Pelaksanaan Pencegahan Diare di Puskesmas Matakali}

\begin{tabular}{|c|c|c|}
\hline Informan & Pernyataan & Terjemahan \\
\hline Petugas Diare & $\begin{array}{l}\text { Ya, dilaksanakan di posyandu, sekolah, dimana } \\
\text { ada wadah kami turun dan tahun ini dilaksanakan } \\
\text { pelatihan kepada kader Posyandu supaya dia juga } \\
\text { tahu to, penyuluhan diare itu bagaimana dan ikut } \\
\text { berperan dalam pencegahan penyakit diare. } \\
\text { Sasarannya itu anak-anak sampai lansia, kadang } \\
\text { juga saya tidak pergi penyuluhan de kalau } \\
\text { dinaska lagi }\end{array}$ & $\begin{array}{l}\text { Penyuluhan dilakukan di } \\
\text { semua tempat dan } \\
\text { sasarannya semua usia. } \\
\text { Tidak melakukan } \\
\text { peyuluhan di lapangan } \\
\text { pada saat rangkap jabatan }\end{array}$ \\
\hline Sanitarian & $\begin{array}{l}\text { Dari dulu, kalau misalnya kegiatan ada } \\
\text { pemberdayaan masyarakat ada baik itu dari } \\
\text { jamban ikut sama program lain kalau ada kasus } \\
\text { diare kami sampaikan ke masyarakat } \\
\text { penyuluhankan tidak harus berkelompok individu } \\
\text { juga, kalau ada pertemuan Desa saya selipkan } \\
\text { penyuluhan juga, musrembang tingkat desa saya } \\
\text { ikutkan, ada kegiatan posyandu ikutkan lagi, } \\
\text { dimana ada wadah saya selipkan lagi } \\
\text { Tidak ada jadwal khusus kita ikut juknis } \\
\text { tersendiri, kalau perprogram itu ada juknisnya } \\
\text { disitu tapi disitu cuman ada pemicuan sanitasi } \\
\text { lingkungan berbasis masyarakat disitu juga kita } \\
\text { bisa masuk selipkan pengukuran, sekaligus } \\
\text { penyuluhan, kayak tadi seleksi kesehatan kantin } \\
\text { sekolah disitu juga ada pencegahan diare dan } \\
\text { ternyata kantin sekolah tidak ada yang memenuhi } \\
\text { keriteria. } \\
\text { Kalau pengolahan sampah rumah tangga cuman } \\
\text { itu ada wadah diangkut sama armada sampah, } \\
\text { kalau daerah perkampungan itu rata-rata dibakar } \\
\text { kalau untuk dibuatkan tempat sampah tidak ada } \\
\text { karena sekolah saja belum semua ada. } \\
\text { Kalau pemeriksaan air dimasyarakat belum baru } \\
\text { fisiknya to. }\end{array}$ & $\begin{array}{l}\text { Rutin melaksanakan } \\
\text { penyuluhan pencegahan } \\
\text { diare baik itu kelompok } \\
\text { maupun individu } \\
\text { Tidak ada jadwal khusus } \\
\text { melakukan penyuluhan, } \\
\text { yang ada itu dalam bentuk } \\
\text { juknis yaitu pemicuan } \\
\text { sanitasi lingkungan } \\
\text { berbasis masyarakat dan di } \\
\text { selipkan dalam } \\
\text { pencegahan diare } \\
\text { Pengolahan sampah rumah } \\
\text { tangga diperkotaan } \\
\text { diangkut oleh armada } \\
\text { sampah sedangkan di } \\
\text { perkampungan rata-rata } \\
\text { dibakar hanya } \\
\text { Pemeriksaan air hanya } \\
\text { bagian fisik belum } \\
\text { sepenuhnya dilakukan }\end{array}$ \\
\hline Masyarakat & $\begin{array}{l}\text { Ada biasa diposyandu, karena biasa ada yang } \\
\text { petugas puskesmas menyampaikan informasi ke } \\
\text { ibu-ibu bersihkanki pekaranganta tutupi } \\
\text { penampungan airta cuci tanganta pakai sabun } \\
\text { sebelum makan dan sesudah membunag tinja bayi. }\end{array}$ & $\begin{array}{lr}\text { Menerima } & \text { saran dari } \\
\text { petugas kesehatan dan } \\
\text { menyadari } & \text { pentingnya } \\
\text { menjaga } & \text { kebersihan } \\
\text { lingkungan } & \end{array}$ \\
\hline
\end{tabular}

Pernyataan Informan Keterlibatan Aktif Pemerintah dalam Pelaksanaan Program Pencegahan Diare di Puskesmas Matakali

\begin{tabular}{|l|l|l|}
\hline \multicolumn{1}{|c|}{ Informan } & \multicolumn{1}{|c|}{ Pernyataan } & \multicolumn{1}{c|}{ Terjemahan } \\
\hline $\begin{array}{l}\text { Kepala } \\
\text { Puskesmas }\end{array}$ & Iya, Pemerintah setempat ikut ambil alih & $\begin{array}{l}\text { Pemerintah setempat ikut } \\
\text { terlibat }\end{array}$ \\
\hline Petugas Diare & Iya, membantu kita dalam pencegahan diare, & Pemerintah setempat \\
\hline
\end{tabular}




\begin{tabular}{|l|l|l|}
\hline & $\begin{array}{l}\text { mauki naterima baik pihak Desa, kan untuk } \\
\text { masyarakatnya juga supaya sehat ii to }\end{array}$ & $\begin{array}{l}\text { membantu kita dalam } \\
\text { pencegahan diare untuk } \\
\text { kesejahteraan masyarakat } \\
\text { setempat }\end{array}$ \\
\hline Sanitarian & $\begin{array}{l}\text { Iya, Mereka membantu mensosialisasikan } \\
\text { pentingya kesehatan lingkungan, sampai ada } \\
\text { yang membantu pembangunan jamban, hampir } \\
\text { semua desa di wilayah Kecamatan Matakali } \\
\text { menganganggarakan itu, dari PU juga ada, } \\
\text { pembangunan IPAL dan MCK }\end{array}$ & $\begin{array}{l}\text { Pelayanan sosial yang ada } \\
\text { di daerah tersebut ikut } \\
\text { berpartisipasi dalam } \\
\text { meningkatkan pelayanan } \\
\text { kesehatan masyatrakat }\end{array}$ \\
\hline Masyarakat & $\begin{array}{l}\text { Iya ikut contonya pemerintah memberikan } \\
\text { bantuan WC ke warga yang belum mempunyai } \\
\text { WC Adapun pemerintah } \\
\text { setempat yang } \\
\text { memberikan bantuan, } \\
\text { berupa WC bagi yang } \\
\text { belum mempunyai. }\end{array}$ \\
\hline
\end{tabular}

Pernyataan Informan Tentang Masyarakat Terlibat Aktif Mendukung Pelaksanaan Program Pencegahan diare Diare di Puskesmas Matakali

\begin{tabular}{|l|l|l|}
\hline \multicolumn{1}{|c|}{ Informan } & \multicolumn{1}{|c|}{ Pernyataan } & \multicolumn{1}{c|}{ Terjemahan } \\
\hline Kepala Puskesmas & $\begin{array}{l}\text { Iya, sebagian yang menyadari akan kesehatan } \\
\text { lingkungan }\end{array}$ & $\begin{array}{l}\text { Sebagian masyarakat } \\
\text { menyadari pentingnya } \\
\text { kesehatan lingkungan }\end{array}$ \\
\hline Petugas Diare & $\begin{array}{l}\text { Sebagian de yang mau berobat, ikut membenahi } \\
\text { diri sadar akan lingkungannya }\end{array}$ & $\begin{array}{l}\text { Sebagian masyarakat yang } \\
\text { ingin berpartisipasi dalam } \\
\text { pencegahan diare }\end{array}$ \\
\hline Sanitarian & $\begin{array}{l}\text { Kalau mendukung, ya mendukung sekali hadirji } \\
\text { kalau ada semacam bantuan tapi kalau, datang } \\
\text { saja dikasi penyuluhan susah sekali kumpul }\end{array}$ & $\begin{array}{l}\text { Lebih mementingkan } \\
\text { keinginan dibandingkan } \\
\text { dengan kebutuhannya. }\end{array}$ \\
\hline Masyarakat & $\begin{array}{l}\text { Nasuruki bersihkan pekarangan, bak mandi. Ya } \\
\text { dilakukani. }\end{array}$ & $\begin{array}{l}\text { Mengikuti perintah } \\
\text { petugas kesehatan }\end{array}$ \\
\hline
\end{tabular}

Pernyataan Informan tentang Hambatan Pelaksanaan Program Pencengahan Diare di Puskesmas Matakali

\begin{tabular}{|c|c|c|}
\hline Informan & Pernyataan & Terjemahan \\
\hline $\begin{array}{l}\text { Kepala } \\
\text { Puskesmas }\end{array}$ & Tidak ada & Hambatan tidak ada \\
\hline Petugas Diare & $\begin{array}{l}\text { Hambatannya itu masyarakat belum sadar hidup } \\
\text { bersih dan sehat, Masyarakat Buang Air di } \\
\text { sembarang tempat, Meminum Air yang belum } \\
\text { dimasak. Susah juga itu to karna orang tua dulu } \\
\text { lebih percaya dengan keyakinan orang dulu, } \\
\text { kayak anak-anak kalau sakit perutnya dikiranya } \\
\text { gigi yang mau tumbuh sehingga nasepelehkan i, } \\
\text { nah kalau persoalan seperti ini lambat }\end{array}$ & $\begin{array}{l}\text { Masyarakat } r \text { setempat } \\
\text { masih mempercayai } \\
\text { budaya tradisi terdahulu } \\
\text { dan tidak menyadari } \\
\text { bahwa yang ia makan } \\
\text { belum tentu steril }\end{array}$ \\
\hline
\end{tabular}




\begin{tabular}{|c|c|c|}
\hline & $\begin{array}{l}\text { penanganannya karna tidak cepat dibawa ke } \\
\text { puskesmas dan sebagian masyarakat juga masi } \\
\text { percaya kalau makanki daun jambu lansung } \\
\text { dipohonnya langsung sembuh padahal itukan } \\
\text { tidak steril }\end{array}$ & \\
\hline Sanitarian & $\begin{array}{l}\text { Kalau hambatannya itu kalau di kesling ya itu } \\
\text { pengolahan sampah dan struktur yang ada } \\
\text { dilapangan, kalau betul kita terapkan } \\
\text { lingkungan yang sehat kita berbicara struktur } \\
\text { juga kayak drainase ada tapi drainasenya lebih } \\
\text { tinggi dari rumah pemukiman otomatis saluran } \\
\text { airnya juga tidak lancar. Masih ada warga juga } \\
\text { dek yang tidak menggunakan Jamban. }\end{array}$ & $\begin{array}{l}\text { Hambatan ada pada } \\
\text { pengolahan sampah, warga } \\
\text { masih membuang tinja } \\
\text { sembarangan dan struktur } \\
\text { yang kurang, contohnya } \\
\text { drainase ada tetapi lebih } \\
\text { tinggi dari pada } \\
\text { pemukiman sehingga } \\
\text { saluran air tidak lancar }\end{array}$ \\
\hline
\end{tabular}

Pernyataan Informan tentang Monitoring dan Evaluasi yang Dilakukan terhadap Pelaksanaan Program Diare

\begin{tabular}{|c|c|c|}
\hline Informan & Pernyataan & Terjemahan \\
\hline $\begin{array}{l}\text { Kepala } \\
\text { Puskesmas }\end{array}$ & $\begin{array}{l}\text { Ada pasien yang masuk dengan pernyakit diare } \\
\text { kita monitoring kita juga melakukan pelaporan } \\
\text { ke Dinas Kesehatan jangan sampai ada KLB }\end{array}$ & $\begin{array}{l}\text { Jika pasien berobat di } \\
\text { Puskesmas ia monitoring } \\
\text { dan melakukan pelaporan } \\
\text { di Dinas Kesehatan agar } \\
\text { tidak terjadi KLB }\end{array}$ \\
\hline Petugas Diare & $\begin{array}{l}\text { Melalui laporan setiap bulannya direkap, lalu } \\
\text { dilihat apakah bertambah atau berkurang } \\
\text { dengan melakukan penyuluhan pencegahan, kita } \\
\text { bisa liat disitu ada penurunan kasus atau tidak }\end{array}$ & $\begin{array}{l}\text { Melakukan rekapan } \\
\text { laporan setiap bulan, } \\
\text { apakah ada penurunan atau } \\
\text { peningkatan kasus diare } \\
\text { setelah } \\
\text { penyuluhan }\end{array}$ \\
\hline Sanitarian & $\begin{array}{l}\text { Hanya seputaran jamban. Jamban yang } \\
\text { diberikan oleh bantuan desa dipergunakan } \\
\text { sebaik mungkin atau tidak }\end{array}$ & $\begin{array}{l}\text { Apakah jamban dari } \\
\text { bantuan desa digunakan } \\
\text { sebaik mungkin atau tidak }\end{array}$ \\
\hline
\end{tabular}

Pernyataan Informan tentang Harapan dari Program Pencegahan Diare di Puskesmas Matakali

\begin{tabular}{|l|l|l|}
\hline \multicolumn{1}{|c|}{ Informan } & \multicolumn{1}{|c|}{ Pernyataan } & \multicolumn{1}{|c|}{ Terjemahan } \\
\hline $\begin{array}{l}\text { Kepala } \\
\text { Puskesmas }\end{array}$ & $\begin{array}{l}\text { Petugas bekerja sesuai dengan prosedur yang } \\
\text { ada, masyarakat peduli akan kesehatan pribadi, } \\
\text { dan pemerintah setempat ikut ambil alih }\end{array}$ & $\begin{array}{l}\text { Petugas bekerja sesuai } \\
\text { dengan prosedur yang ada, } \\
\text { masyarakat peduli akan } \\
\text { kesehatan pribadi, dan } \\
\text { pemerintah setempat ikut } \\
\text { terlibat }\end{array}$ \\
\hline Petugas Diare & $\begin{array}{l}\text { Yang saya harapkan kedepannya mudah } \\
\text { mudahan angka kesakitan diare di Kecamatan } \\
\text { Matakali menurun dan tidak terjadi lagi } \\
\text { kematian }\end{array}$ & $\begin{array}{l}\text { Herapan kedepannya } \\
\text { angkan kesakitan diare } \\
\text { menurun dan tidak terjadi } \\
\text { lagi kematian }\end{array}$ \\
\hline Sanitarian & $\begin{array}{l}\text { Mudah mudahan masyarakat sadar akan } \\
\text { pentingnya menjaga kebersihan lingkungan agar }\end{array}$ & $\begin{array}{l}\text { Masyarakat sadar akan } \\
\text { kebersihan lingkungan }\end{array}$ \\
\hline
\end{tabular}




\begin{tabular}{|l|l|l|}
\hline & $\begin{array}{l}\text { tidak terjadi lagi kasus diare. } \\
\text { Saya maunya agar pemukiman di Kecamatan } \\
\text { Matakali sehat }\end{array}$ & $\begin{array}{l}\text { sehingga tidak terjadi lagi } \\
\text { kasus diare dan } \\
\text { pemukiman warga menjadi } \\
\text { sehat }\end{array}$ \\
\hline Masyarakat & $\begin{array}{l}\text { Semoga sering dilakukan penyampaian di } \\
\text { masyarakat untuk menjaga kebersihan }\end{array}$ & $\begin{array}{l}\text { Lebih meningkatkan } \\
\text { penyampain informasi } \\
\text { mengenai PHBS }\end{array}$ \\
\hline
\end{tabular}

\section{Pernyataan Informan Tentang Saran yang Diajukan untuk Perbaikan Pelaksanaan dari} Program Pencegahan Diare di Puskesmas Matakali

\begin{tabular}{|c|c|c|}
\hline Informan & Pernyataan & Terjemahan \\
\hline $\begin{array}{l}\text { Kepala } \\
\text { Puskesmas }\end{array}$ & Kalau ada penyakit diare diobati segera & $\begin{array}{l}\text { Mengambil tindakan } \\
\text { secepat mungkin bila } \\
\text { terjadi penyakit diare }\end{array}$ \\
\hline Petugas Diare & $\begin{array}{l}\text { Untuk program pencegahan diare maksudnya } \\
\text { pengelolah bukan bekerja sendiri tapi bagaimana } \\
\text { cara kita bekerja sama dengan program-program } \\
\text { yang terkait, pemerintah setempat misalnya dalam } \\
\text { hal diare kan berbasis lingkungan toh jadi kita } \\
\text { harus melibatkan juga pegawai dari keslingnya } \\
\text { bagaimana jamban, jumlah jamban dan air bersih } \\
\text { terus kita bekerja sama dengan promosi kesehatan } \\
\text { karna dia terutama yang selalu turun berkoar- } \\
\text { koar di masyarakat toh, } \\
\text { Pemerintah setempat juga sosialisasi } \\
\text { kemasyarakat tentang kesehatan berbasis } \\
\text { lingkungan, betul-betul itu aparat desa, dusun } \\
\text { atau yang lain-lain, betu betul harus bias } \\
\text { nasosialisaikan ke masyarakatnya haruski sadar } \\
\text { haruski punya sarana air bersih punya jamban } \\
\text { juga. }\end{array}$ & $\begin{array}{l}\text { Bekerja sama } \\
\text { program-program }\end{array}$ \\
\hline Sanitarian & $\begin{array}{l}\text { Ya kerjasama lintas sektor yang semakin baik } \\
\text { karenatidak berhasil itu program dek kalau tidak } \\
\text { ada kerjasama lintas sektor dan lintas program. }\end{array}$ & $\begin{array}{l}\text { Bekerjasama dengan } \\
\text { lintas sektor dan lintas } \\
\text { program yang semakin } \\
\text { baik }\end{array}$ \\
\hline
\end{tabular}




\section{PEMBAHASAN}

Upaya pencegahan diare meliputi: Penyehatan Lingkungan dan Penyuluhan yaitu sebagai berikut :

\section{Penyuluhan Kesehatan}

Penyuluhan adalah ilmu sosial yang mempelajari sistem dan proses perubahan individu serta masyarakat agar dapat terwujud perubahan yang lebih baik sesuai dengan yang diinginkan(Setiana. L. 2005)

Berdasarkan hasil wawancara dengan petugas diare Puskesmas Matakali, pemberian informasi tentang diare dan penanganan terjadinya diare dilakukan melalui penyuluhan yang bertujuan untuk memberdayakan masyarakat sehingga mampu untuk mengatasi masalah kesehatannya sendiri. Kegiatan penyuluhan dilakukan di posyandu dan sekolah.

Dengan kata lain dengan adanya penyuluhan tersebut diharapkan dapat membawa akibat terhadap perubahan perilaku kesehatan dari sasaran (Notoatmodjo, 2010). Sehingga mengurangi kasus diare.

Berdasarkan hasil wawancara dengan petugas diare bahwa media yang digunakan dalam melakukan penyuluhan adalah media seperti poster, leaflet dan lembar balik penyuluhan hanya saja lembar balik penyuluhan yang digunakan kurang lengkap dan organisasi masyarakat tidak terlibat melakukan penyuluhan.

Penyuluhan yang dilakukan di masyarakat selama ini kurang berhasil. Lebih menonjolkan sisi kuratif yang diberikan kepada masyarakat selama ini dan lebih banyak menerima informasi mengenai penanganan diare. Dipengaruhi oleh frekuensi penyuluhan dan tehnik komunikasi yang digunakan. Teknik komunikasi yang digunakan lebih banyak menggunakan konseling tanpa menggunakan media lain (Riri Astika Indriani, 2014). Untuk itu dalam melakukan penyuluhan diare sebaiknya menggunakan media yang lengkap dan organisasi masyarakat juga terlibat dalam melakukan penyuluhan.

Kader diharapkan dapat berperan sebagai pemberi informasi kesehatan kepada masyarakat, penggerak masyarakat untuk melaksanakan pesanpesan kesehatan seperti mendatangi posyandu dan melaksanakan hidup bersih dan sehat. Disamping itu kader juga dapat berperan sebagai orang yang pertama kali menemukan jika ada masalah kesehatan di daerahnya dan segera melaporkan ke tenaga kesehatan setempat. Kader merupakan penghubung antara masyarakat dengan tenaga kesehatan karena kader selalu 
berada di tengah-tengah masyarakat (Kemenkes RI, 2010).

\section{Penyehatan Lingkungan}

Berdasarkan wawancara dengan petugas kesling diketahui bahwa masih ada penduduk wilayah Puskesmas Matakali yang buang air besar (BAB) sembarangan seperti di drainase sawah dan kebun. Hal tersebut tentunya berkaitan dengan kepemilikan jamban dan merupakan salah satu faktor terjadinya penyakit diare.

\section{Penelitian}

Kamaruddin menunjukkan bahwa faktor lingkungan yaitu ketersediaan jamban, sumber air bersih, tempat pembuangan sampah dan hygiene perorangan ada hubungan kejadian diare (Kamaruddin 2004). Penggunaan jamban oleh masyarakat yang berada di wilayah kerja Puskesmas Matakali Masih perlu karena masih ada beberapa masyarakat yang tidak memiliki jamban.

Dari hasil wawancara dengan Petugas kesehatan lingkungan diketahui bahwa kesadaran masyarakat dalam menjaga kebersihan lingkungan dinilai masih rendah, pengelolaan sampah tidak terkelola dengan baik, masyarakat masih ada yang buang sampah sembarangan ke drainase sawah dan di pekarangan rumah. Rendahnya partisipasi masyarakat dikarenakan rendahnya pemberdayaan masyarakat yang dilakukan selama ini. Masyarakat hanya sekedar tahu bahwa lingkungan yang kotor dapat menimbulkan penyakit tanpa mau dan mampu untuk berbuat. Hal tersebut dikarenakan kurangnya pendekatan yang dilakukan oleh pemerintah. Pemerintah harus lebih dekat dengan masyarakat dan menanamkan kesadaran masyarakat bahwa kebersihan itu penting untuk mencegah penularan penyakit dan keterlibatan masyarakat dalam hal itu sangat dibutuhkan.

Hal ini sejalan dengan pendapat Friedmann, dalam mengambil keputusan atau bertindak positif oleh Pemerintah dapat mempengaruhi peningkatan partisipasi masyarakat dalam suatu kegiatan (Friedmann 1992). Kegiatan yang dilakukan oleh tenaga kesehatan dalam hal penyehatan lingkungan yang harus bekerja sama dengan pemerintah setempat meliputi : pemeriksaan sanitasi rumah penduduk, pemeriksaan bakteriologis perusahaan air minum isi ulang, penyuluhan PHBS dan menjalin kerjasama dengan masyarakat setempat baik itu tokoh adat, agama dan pemuda. 
Hambatan dalam kegiatan penyehatan lingkungan adalah rendahnya peran serta masyarakat untuk ikut bertanggung jawab menjaga kebersihan lingkungan. Masyarakat menganggap bahwa penyakit diare itu tidak terlalu berbahaya tetapi sebaliknya, karena dapat mengakibatkan kematian.

Dalam rangka menyukseskan pembangunan nasional, khususnya di bidang kesehatan, bentuk pelayanan kesehatan diarahkan pada prinsip bahwa masyarakat bukanlah sebagai objek tetapi merupakan subjek dari pembangunan itu sendiri. Pada hakikatnya, kesehatan dipolakan mengikut sertakan masyarakat secara aktif dan bertanggung jawab (Efendi, 2009).

Berdasarkan hasil wawancara dengan petugas diare dan kesehatan lingkungan bahwa penyebab utama penyakit diare di Puskesmas Matakali itu dari segi makanan karena seringnya mengkonsumsi makanan siap saji yang kebersihannya tidak dijamin. Selain itu, lingkungan juga bisa mempengaruhi seperti wc dan drainase yang belum memadai. Program penyuluhan dan penyehatan lingkungan yang dilakukan di masyarakat dalam penurunan kasus diare tidak terlalu berpengaruh karena masih adanya masyarakat yang tidak peduli dengan kebersihannya.

Dalam program perawatan kesehatan dasar di pedesaan, intervensi perawatan anak efektif dalam penurunan kasus diare pada anak, tetapi efek ini tidak merata terhadap status sosial ekonomi rumah tangga. Jadi, harus diperhatikan ketika intervensi perawatan anak dilaksanakan di pedesaan Cina untuk mengurangi diare pada anak-anak (Hong Yan, 2018).

\section{KESIMPULAN}

Peran dari tenaga kesehatan sangat dibutuhkan agar program diare dapat berjalan secara optimal. Di Puskesmas Matakali, tenaga kesehatan yang terlibat dalam mendukung pelaksanaan program diare tidak hanya petugas diare, promkes dan tenaga kesehatan lingkungan selain itu pemerintah juga berperan dalam pelaksanaan program. Penyuluhan diare kurang maksimal karena adanya rangkap jabatan oleh P2p diare. Masih rendahnya partisipasi masyarakat dalam menjaga kebersihan lingkungan seperti pengolahan sampah dan penggunaan jamban yang masih belum menyeluruh dalam mendukung pelaksanaan program diare masih rendah hal ini diakibatkan kurangnya kesadaran masyarakat serta 
kurangnya pengawasan pemerintah setempat terhadap keterlibatan masyarakat dan masih melakukan kebiasaan-kebiasaan terdahulu.

\section{SARAN}

Diharapkan kepada Puskesmas agar penyuluhan diare direncanakan dengan baik secara lanjut. Hal ini bertujuan untuk meningkatkan pengetahuan dan keterampilan masyarakat dapat memahami bahayanya penyakit diare dan peduli akan kesehatan lingkungan. Diharapkan kepada masyarakat di wilayah kerja Puskesmas Matakali agar sadar, akan pentingnya kebersihan lingkungan, tidak membuang sampah sembarangan, tidak buang air besar (BAB) sembarangan, serta spal rumah tangga diperbaiki lagi.

\section{UCAPAN TERIMA KASIH}

Tak lupa saya ucapkan terima kasih kepada kedua orang tua saya, yang selama ini mendoakan saya dan memberi dukungan, baik itu motivasi maupun materi sehingga bisa menyelesaikan skripsi ini dan ucapan terima kasih kepada Kepala Puskesmas Matakali yang telah memberikan izin dalam melakukan penelitian ini, dan pemegang program diare dan petugas sanitarian serta masyarakat penderita diare yang telah meluangkan waktunya untuk membantu dan memperlancar penelitian ini dan terima kasih juga kepada semua pihak yang telah membantu dalam penelitian ini baik itu kepada Bapak Muh.Anwar,SKM.,MPH selaku pembimbing I dan Patmawati,SKM.,M.Kes selaku pembimbing II, dengan segala ketulusan hati telah meluangkan waktu, tenaga dan pemikirannya untuk memberi petunjuk dan arahan dalam menyelesaikan skripsi ini. 


\section{DAFTAR PUSTAKA}

Dinas Kesehatan Provinsi Sulawesi Barat. 2016. Profil Kesehatan Sulawesi Barat. Mamuju.

Dinas Kesehatan Polewali Mandar. 2018. P2P Diare. Polewali.

Departemen Kesehatan Republik Indonesia. 2011. Buku Saku Petugas Kesehatan Lintas Diare. Jakarta.

Efendi, F. dan Makhfudli.2009. Keperawatan Kesehatan Komunis. Salemba Medika.

Gao Wenlong, Guirong Li, Hong Yan dkk. Tahun 2018. Dampak Intervensi "Perawatan Anak" di pedesaan Program Perawatan Kesehatan Utama pada prevalensi diare pada anak-anak kurang dari 36 bulan di pedesaan barat Cina. (Online), (http://doi.org/10.1186/s12887 -0181172-1, diakses 10 november 2018).

Indriani, Riri Astika. 2014. Analisis Pelaksanaan Program Diare di Puskesmas Medan Deli Kecamatan Medan Deli. Skripsi. Medan. Universitas Sumatera Utara.

Kementrian Kesehatan Republik Indonesia. 2013. Riset Kesehatan Dasar. Jakarta.
Kementrian Kesehatan Indonesia. 2016. Profil Kesehatan Indonesia. Jakarta.

Masyuni. 2010. Implementasi Program Prmosi Pencegahan Diare pada Anak Berusia dibawah 3 tahun. Tesis. Surakarta. Universitas Sebelas Maret.

Puskesmas Matakali, 2018. Profil Puskesmas Matakali. Matakali.

Rukmini dkk, Tahun 2010. Analisis Sistem Surveilans Diare Puskesmas Tambak Rejo. (Online), (http://www.scribd.com, diakses 07 Maret 2018).

Sasmitawati. 2011. Jangan Sepelekan Diare. Jakarta: Sunda Kelapa Pustaka.

Wiratna, Sujarweni. 2014. Metodologi Penelitian Keperawatan. Yogyakarta: Gava Media.

Wati, Cucu Sita. 2016. Hubungan Persepsi, Tingkat Pendidikan dan Sosial Ekonomi Ibu dengan Penanganan Pertama Diare pada Balita dirumah pada Wilayah Puskesmas Kemangkoh. Skripsi. Purwokerto. Universitas Muhammadiyah.

Wijoyo. 2013. Diare Pahami Penyakit dan Obatnya. Yogyakarta: Citra Aji 